\title{
Saudi Female Teachers' Perceptions of the Use of L1 in EFL Classrooms
}

\author{
Bayan Al-Hashemi Al-Amir ${ }^{1}$ \\ ${ }^{1}$ English Language Institute, King Abdulaziz University, Kingdom of Saudi Arabia \\ Correspondence: Bayan Al-Hashemi Al-Amir, English Language Institute, King Abdulaziz University, Kingdom \\ of Saudi Arabia. E-mail: Bayan.AlHashemi.1413@gmail.com
}

Received: March 1, 2017 Accepted: May 20, 2017 Online Published: May 26, 2017

doi: 10.5539/elt.v10n6p12 URL: http://doi.org/10.5539/elt.v10n6p12

\begin{abstract}
In the literature of second language teaching and learning, the use of students' first language (L1) has been an issue of debate for many years. Despite the changing state of teaching and learning aspects over the years, the belief that L1 should not be used in English as a Foreign Language (EFL) classrooms has stood the test of time. Nevertheless, many studies have recently started to put this belief under question and to give the effectiveness of L1 use, the benefit of doubt. This paper investigates EFL teachers' perceptions of the use of students' first language at one of the universities in Jeddah, Saudi Arabia, given the fact that those teachers speak students' native language and have different English language proficiency levels. The data gathered through a questionnaire were analyzed using the IBM Statistical Package for Social Science (SPSS)® to find frequencies, percentages and mean scores. The overall results of the study show that the majority of teachers agree to the use of students' first language in their EFL classrooms. Moreover, when investigating the relationship between teachers' English language proficiency level and their perceptions of L1 use, the results suggest that there is no correlation between the two. Furthermore, the results of the study conclude that EFL teachers are selective when it comes to the areas of language teaching where L1 is used.
\end{abstract}

Keywords: teachers' perceptions, use of L1, EFL classrooms, Saudi Arabia

\section{Introduction}

In the literature of second language teaching and learning, the use of students' first language (L1) has been an issue of debate for many years. From the 1840s to the 1940s, second language teaching and learning has been dominated by the Grammar-Translation method whose goal was for students to translate from and into their own native language (Richards \& Rodgers, 2014). Advocates of this method emphasized the use of students' mother tongue (MT) as a medium of instruction and communication (Kelly \& Bruen, 2014). However, later on, with the emergence of the Direct Method, the view of L1 use in second language classrooms has drastically changed. Advocates of the Direct Method have shed light on the importance of intensively exposing students to the target language. Therefore, the use of L1 was strongly prohibited for both, teachers and students (Larsen-Freeman, 2012).

Despite the changing state of teaching and learning aspects over the years, the belief that L1 should not be used in the EFL classroom has stood the test of time. Nevertheless, many studies have recently started to put this belief under question and to give the effectiveness of L1 use the benefit of doubt.(Schweers Jr, 1999), for example, conducted a study through which two benefits of the use of L1 were highlighted. First, it was found that learning a second language can be improved by comparing and contrasting L1 and L2. Secondly, the judicious use of L1 was found to be beneficial as means of cultural expression and communication.

In a critique of the prohibition of L1 use, Butzkamm (2003) indicated that the reason behind the strongly held belief in monolingualism is the huge number of native speakers who don't speak the language of their students. In the light of this assertion, one can assume that teachers who speak students' native languages are more likely to realize the benefits of using L1 in EFL classrooms. The purpose of this study is to test the validity of this hypothesis by investigating teachers' perceptions of the use of L1 in EFL classrooms at one of the English language institutes at a prominent university in Jeddah. 


\subsection{Literature Review}

There have been many studies conducted on the perceptions of teachers towards the use of L1 in EFL classrooms. However, the degree to which teachers believe in the use of L1 and its importance varies from one study to another. Kelly and Bruen (2014) conducted a study which aimed at investigating teachers and students' views of the use of L1 in the higher education levels. The results of their study showed that teachers took a neutral stance in such a matter and accepted the use of L1 in limited conditions, for example, when explaining high level concepts and when creating a relaxed environment for students. Furthermore, Cook (2010, cited in Larsen-Freeman, 2011) asserted that the use of L1 builds a relationship between different languages and follows the pedagogical principles of going from the known to the unknown.

When investigating students' perception of the subject matter, Brooks-Lewis (2009) has conducted a study through which he found that learners view the use of L1 as beneficial and needed. Students, in the study, indicated that the use of L1 decreases anxiety, allows them to bring their life experiences to the classroom, and creates an effective learning environment.Butzkamm (2003), furthermore, argued that using the mother tongue is not only unavoidable but also vital. Without it, there would be no comprehension since learning new meanings is associated with linking these meanings with L1. This connection, however, stops when the learner develops a new network for $\mathrm{L} 2$.

Despite the recent growing change in the view of L1 use when compared to how it was before, many teachers still believe that no other language should be used in class except the target one. When investigating the reasons behind this belief, Butzkamm (2003) concluded that the reason behind teachers' beliefs in monolingualism is the huge number of native speakers, who don't speak the language of their students, and the production of textbooks that are only restricted to English.

When relating teachers' proficiency level in the target language to their use of L1 in classroom, Kang (2013) conducted a study through which he reported that teachers with low proficiency in English highly relied on L1 more than on the target language, whereas teachers with high proficiency level did the opposite. However, what is most intriguing about Kang's (2013) study is the small number of participants, for only two teachers were put under investigation. Linking teachers' proficiency level to their classroom practices requires more than merely conducting a case study. Such a generalization should be made based on larger observations and investigations. Therefore, it seems that Kang's (2013) results are questionable and require more investigation.

Based on these studies, one can generally assume that teachers' proficiency level in the target language and their knowledge of students' L1 play significant roles in whether or not to believe in the use of L1. The present study investigates EFL teachers' perceptions of L1 use in classroom at one of the universities of Jeddah and whether their perceptions are actually affected by their English proficiency level or not. It aims at answering following questions.

\subsection{Research Questions}

- Are EFL teachers, who speak students' native language, with or against the use of students' first language in EFL classrooms?

- Is there a correlation between teachers' second language proficiency levels and their perceptions of the use of L1 in EFL classrooms?

- What areas of language teaching do EFL teachers believe L1 should be used for?

\section{Method}

\subsection{Instrument}

The main tool in this study is a questionnaire adapted from Manara' (2007) study. The reason behind choosing a questionnaire as the main instrument in the current study is the fact that it is one of the most prevalent methods of collecting data on perspectives, perceptions, beliefs and attitudes (Gass, Mackey, \& Ross - Feldman, 2005).

The questionnaire, available in Appendix A, was slightly modified according to the variables involved in the study. The first part investigates demographic information about the participants; such as their gender, their native language and their English proficiency level. The second part investigates teachers' opinions towards the use of English in the classroom, followed by questions that aim at investigating teachers' perceptions of the use of students' L1 and the use of bilingual materials in the classroom. The third part of the questionnaire aims at identifying the most common areas of language teaching in which L1 is believed to be necessary. 


\subsection{Participants}

The questionnaire was distributed to the whole population which is around fifty-five EFL female teachers in the academic year 2016-2017. The study targets teachers whose native language is Arabic or who can speak Arabic very well. The reason behind targeting those teachers who speak Arabic is to ensure the accuracy of the results and to prevent any possible deviations from taking place. Nevertheless, only 31 teachers responded to the questionnaire, representing $56 \%$ of the whole population.

To get an overall idea of teachers' English language proficiency level, teachers were required to give their IELTS scores or their TOEFL equivalents. The following table shows the participants' English language proficiency scores.

Table 1. IELTS \& TOEFL scores of teacher participants

\begin{tabular}{lll}
\hline Score & Frequency & Percentage \\
\hline TOEFL: 46-59, IELTS: 5.5 & 1 & 3.2 \\
TOEFL: 60-78, IELTS: 6 & 6 & 19.4 \\
TOEFL: 79-93, IELTS: 6.5 & 10 & 32.3 \\
TOEFL: 94-101, IELTS: 7 & 9 & 29.0 \\
TOEFL: $102-109$, IELTS: 7.5 & 3 & 9.7 \\
TOEFL: $110-114$, IELTS: 8 & 2 & 6.5 \\
Total & 31 & 100.0 \\
\hline
\end{tabular}

As the table shows, teachers vary according to their levels of English language proficiency; $16.2 \%$ of the participants are classified as 'very good users', a significant proportion of 61.3 are described as 'good users' (IELTS Score 6.5 and 7), whereas the others fit into 'competent users'. Appendix B shows the IELTS band scores.

\subsection{Data Analysis}

To analyze the data, the Statistical Package for Social Science (SPSS) was used to find the frequencies, percentages and mean scores. Moreover, to investigate the correlation between teachers' perceptions of the use of L1 and their English proficiency level, the SPSS was also used to calculate the Pearson Correlation Coefficient.

\section{Results and Discussion}

\subsection{Question 1}

Are EFL teachers who speak students' native language with or against the use of students' first language in EFL classrooms?

To answer this question, the first section of the questionnaire was divided into two parts. The first part investigates teachers' beliefs towards the extent to which English is to be used in EFL classroom. The second part, on the other hand, focuses on their perceptions of the use of students' L1. The following part shows the results of both sections.

\subsubsection{Teachers' Perceptions of the Use of English}

There were three questions in the questionnaires related to the use of English as the only medium of instruction and communication. The following table summarizes the results of the data. 
Table 2. Mean and standard deviations of teachers' perceptions of the use of English

\begin{tabular}{llll}
\hline Statements & Instructors & & \\
& Mean & Std. D & Rank \\
\hline 1.When communicating with the teacher, students should only use English & 3.23 & .560 & 1 \\
2. Students should only use English when communicating with their classmates. & 2.84 & .860 & 3 \\
$\begin{array}{l}\text { 3. Teachers should use English the entire time, regardless how much English the } \\
\text { students use. }\end{array}$ & 2.87 & .806 & 2 \\
ALL & 2.98 & .742 & - \\
\hline
\end{tabular}

As Table 2 shows, the overall mean and standard deviation of the participants' responses are 2.98 and 0.742 , respectively, indicating that EFL teachers agree that English should be the only language used by both, teachers and students, in the classroom.

\subsubsection{Teachers' Perceptions of the Use of L1}

Questions 4-8 in the questionnaire aimed at figuring out teachers' perceptions of the use of students' L1 in the EFL classrooms. The following table summarizes the results of teachers' responses.

Table 3. Mean and standard deviations of teachers' perceptions of the use of L1

\begin{tabular}{|c|c|c|c|}
\hline \multirow{2}{*}{ Statements } & \multicolumn{3}{|c|}{ Instructors } \\
\hline & Mean & Std. D & Rank \\
\hline $\begin{array}{l}\text { 4. The use of students' mother tongue slows down the process of } \\
\text { acquiring English }\end{array}$ & 2.42 & .886 & 4 \\
\hline $\begin{array}{l}\text { 5. Once I use students' mother tongue, my students always expect me to } \\
\text { explain things in their mother tongue }\end{array}$ & 1.97 & .706 & 5 \\
\hline $\begin{array}{l}\text { 6. Comparing students' mother tongue and English helps students to } \\
\text { acquire English }\end{array}$ & 2.68 & .748 & 3 \\
\hline $\begin{array}{l}\text { 7. Students learn better using bilingual materials (materials with little } \\
\text { use of mother tongue, e.g. instruction in Arabic and exercises written in } \\
\text { English) }\end{array}$ & 2.81 & .792 & 2 \\
\hline $\begin{array}{l}\text { 8. Students learn better using bilingual dictionaries (Arabic-English } \\
\text { instead of English-English dictionary) }\end{array}$ & 2.87 & .763 & 1 \\
\hline ALL & 2.55 & .779 & - \\
\hline
\end{tabular}

Although Table 2 shows that teachers agree to the use of English as the only medium of instruction and communication in the classroom, Table 3 shows that they also agree to the use of L1 in EFL classrooms. The overall mean and SD of the participants are 2.55 and 0.779 , respectively, suggesting that EFL teachers accept the use of L1 as well.

This contradiction between the results of part A and part B can be attributed to two factors. The first one is the stereotypical image, created by the Direct Method, that L1 is strongly prohibited in EFL classrooms. Secondly, teachers' feelings when using L1 in the classroom might have affected their responses in part A. When the teachers were asked about their feelings when using L1, their answers were as follows: 


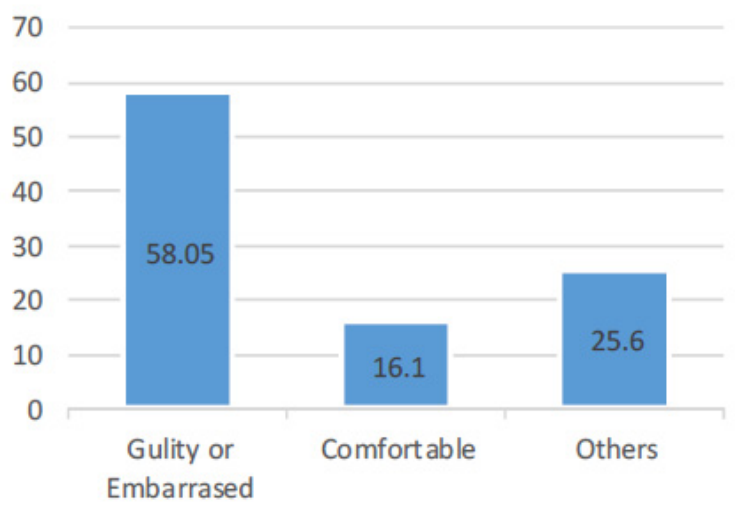

Figure 1. Teachers' feelings when using 11 in the classroom

As Figure 1 shows, over half of the teachers feel guilty whenever they use students' native language, whereas only a minority of them indicated that they feel comfortable. The other responses range between 'unsatisfied' and 'confident'.

To better answer question 1, the results of the first section of the questionnaire suggest that teachers acknowledge the benefits of using L1 in EFL classrooms on certain occasions. Accordingly, the results are compatible with what other researchers have found about such a use ((Brooks-Lewis, 2009; Butzkamm, 2003; Kelly \& Bruen, 2014; Schweers Jr, 1999).

\subsection{Question 2}

Is there a correlation between teachers' second language proficiency levels and their perceptions of the use of L1 in EFL classrooms?

English language proficiency level varies among participants. In order to investigate its relationship with teachers' perceptions of the use of L1 and L2, the Pearson correlation coefficient in the SPSS was used. The following table summarizes the results:

Table 4. Correlation between Teachers' Proficiency Levels and Their perceptions of the Use of L1

\begin{tabular}{llll}
\hline Teachers' perceptions & & & comment \\
\hline \multirow{3}{*}{$\mathrm{A}(1-3)$} & Pearson Correlation & $-.326-$ & \\
& Sig. (2-tailed) & .074 & No correlation \\
& $\mathrm{N}$ & 31 & \\
$\mathrm{~B}(4-8)$ & Pearson Correlation & -.079 & \\
& Sig. (2-tailed) & .672 & No correlation \\
& $\mathrm{N}$ & 31 & \\
\hline
\end{tabular}

Based on the results of Table 4, two major conclusions can be drawn. First, there is no correlation between teachers' perceptions of only using the target language in EFL classrooms and their IELTS or TOEFL scores. Second, there is no correlation between EFL teachers' perceptions of the use of L1 in EFL classrooms and their IELTS or TOEFL scores. These results contradict Kang's (2013) assertion that teachers with low proficiency in English are more likely to use L1 in the classroom, and vice versa.

\subsection{Question 3}

In what areas of language teaching L1 should be used?

The last part of the questionnaire required teachers to identify the areas of language teaching they believe L1 should be used in. The following figure shows these areas in correspondence with teachers' perceptions. 


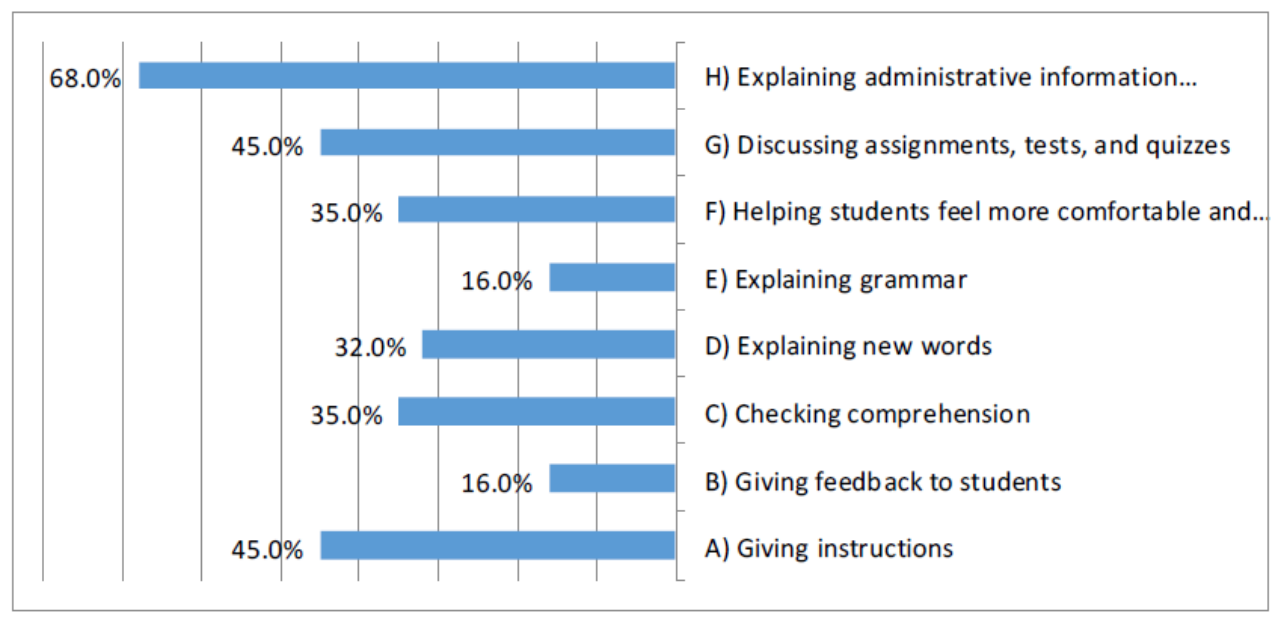

Figure 2. Areas of language teaching that requires the use of L1

As Figure 2 suggests, when teachers use L1 in classroom, a significant proportion of approximately over two third believe that L1 should be used when explaining administrative information, whereas more than two fifths of the teachers believe that it should be used when giving instructions and when discussing assignments. Furthermore, when lowering students' psychological barriers, more than a third of the participants believe that L1 should be incorporated and used. When it comes to the areas of language teaching where the subject matter is involved, more than a third of the teachers believe that L1 should be used to check students' comprehension, and a third of them believe that it should be used when explaining new words. However, a minority of less than a fifth believe that L1 is to be used when explaining grammar or when providing students with feedback. These results support the results of other studies (Kelly \& Bruen, 2014; Schweers Jr, 1999) which suggest that EFL teachers support the judicious and selective use of L1 in the classroom.

\section{Conclusion}

The present study intended to investigate teachers' perceptions of the use of L1 in EFL classrooms at one of the English language institute at a prominent university in the city of Jeddah in Saudi Arabia, given the fact that they speak students' native language and obtain different English language proficiency levels. As such, the results of the study suggest that EFL teachers agree to the use of L1 in their classrooms. Moreover, it shows that there is no relationship between teachers' English language proficiency level and their perceptions of the use of L1. Finally, the results, also, indicate that teachers believe in the judicious and selective use of L1.

The aim of the current study was not to make a stance against the norm or to lay down the importance of solely exposing students to the target language. Rather, it aims at investigating teachers' perceptions of L1 use, given the fact that teachers represent an important element in the teaching/learning process. Therefore, based on the results of this study, EFL teachers are encouraged to expand their knowledge about the role of students' native language and to reconsider the moderate use of it.

To conclude, it is important to note that conducting follow-up interviews with the participants would have helped increasing the reliability of teachers' responses and solving the contradiction between their perceptions of the use of L1 and L2. However, due to the fact that this study has been conducted over a short period of time, the participants could not be interviewed. Therefore, further studies can use a questionnaire supported by follow-up interviews and classroom observations.

\section{References}

Brooks-Lewis, K. A. (2009). Adult learners' perceptions of the incorporation of their L1 in foreign language teaching and learning. Applied Linguistics, 30(2), 216-235. https://doi.org/10.1093/applin/amn051

Bruen, J., \& Kelly, N. (2014). Using a shared L1 to reduce cognitive overload and anxiety levels in the L2 classroom. The Language Learning Journal, 1-14. https://doi.org/10.1080/09571736.2014.908405

Butzkamm, W. (2003). We only learn language once. The role of the mother tongue in FL classrooms: death of a dogma. Language learning journal, 28(1), 29-39. https://doi.org/10.1080/09571730385200181

IELTS. (2012). IELTS Guide for Teachers. Retrieved December 22, 2016, from 
https://www.britishcouncil.it/sites/default/files/ielts_guide_for_teachers_italy.pdf

Kang, D.-M. (2013). EFL teachers' language use for classroom discipline: A look at complex interplay of variables. System, 41(1), 149-163. https://doi.org/10.1016/j.system.2013.01.002

Larsen-Freeman, D. (2012). The emancipation of the language learner. Studies in Second Language Learning and Teaching(II-3), 297-309. https://doi.org/10.14746/ssllt.2012.2.3.2

Mackey, A., \& Gass, S. M. (2015). Second language research: Methodology and design. Routledge.

Manara, C. (2007). The Use of L1 Support: Teachers' and Students' Opinions and Practices in an Indonesian Context. The Journal of Asia TEFL, 4, 145-178.

Richards, J. C., \& Rodgers, T. S. (2014). Approaches and methods in language teaching: Cambridge university press.

Schweers, Jr, C. W. (1999). Using L1 in the L2 classroom. Paper presented at the English teaching forum.

\section{Appendix A}

\section{Questionnaire:}

\section{Demographic information:}

Participant's Name:

Sex:

Years of experience:

Job title:

Mother tongue:

Your IELTS or TOEFL score:
A) TOEFL: 0-31, IELTS: 0-4
B) TOEFL: 32-34, IELTS: 4.5
C) TOEFL: 35-45, IELTS: 5
D) TOEFL: 46-59, IELTS: 5.5
E) TOEFL: 60-78, IELTS: 6
F) TOEFL: 79-93, IELTS: 6.5
G) TOEFL: 94-101, IELTS: 7
H) TOEFL: 102-109, IELTS: 7.5
I) TOEFL: 110-114, IELTS: 8
J) TOEFL: 115-117, IELTS: 8.5
K) TOEFL: 118-120, IELTS: 9

How often do you use L1 in class?
A) Never.
B) Rarely.
C) Often.
D) Usually.
E) Always.

\section{Please click on your response to the items.}

1. When communicating with the teacher, students should only use English.
A) Agree.
B) Strongly agree. 
C) Disagree.

D) Strongly disagree.

2. Students should only use English when communicating with their classmates.
A) Agree.
B) Strongly agree.
C) Disagree.
D) Strongly disagree.

3. Teachers should use English the entire time, regardless how much English students choose to use.
A) Agree.
B) Strongly agree.
C) Disagree.
D) Strongly disagree.

4. The use of students' mother tongue slows down the process of acquiring English
A) Agree.
B) Strongly agree.
C) Disagree.
D) Strongly disagree.

5. Once I use students' mother tongue, my students always expect me to explain things in their mother tongue.
A) Agree.
B) Strongly agree.
C) Disagree.
D) Strongly disagree.

6. Comparing students' mother tongue and English helps students to acquire English.
A) Agree.
B) Strongly agree.
C) Disagree.
D) Strongly disagree.

7. Students learn better using bilingual materials (materials with little use of mother tongue, e.g. instruction in Arabic and exercises written in English)
A) Agree.
B) Strongly agree.
C) Disagree.
D) Strongly disagree.

8. Students learn better using bilingual dictionaries (Arabic-English instead of English-English dictionary)
A) Agree.
B) Strongly agree.
C) Disagree.
D) Strongly disagree.

1. In your opinion, what is students' mother tongue supposed to be used for? (You can choose more than one)
A) Giving instructions
B) Giving feedback to students.
C) Checking comprehension.
D) Explaining new words 
E) Explaining grammar

F) Helping students feel more comfortable and confident in the classroom

G) Discussing assignments, tests, and quizzes

H) Explaining administrative information (syllabus, announcements, deadlines, etc.)

I) Others:

2. How do you feel when you use students' L1 in the classroom?
A) Guilty or embarrassed.
B) Comfortable.
c) Other:

\section{Appendix B:}

IELTS Band Scores (IELTS Guide for Teachers, 2012)

\begin{tabular}{|c|c|c|}
\hline Band & User & Description \\
\hline 9 & Expert user & $\begin{array}{l}\text { Has fully operational command of the language; appropriate, accurate, fluent } \\
\text { with complete understanding. }\end{array}$ \\
\hline 8 & Very good user & $\begin{array}{l}\text { Has fully operational command of the language with only occasional } \\
\text { unsystematic inaccuracies and inappropriacies. Misunderstandings may occur in } \\
\text { unfamiliar situations. }\end{array}$ \\
\hline 7 & Good user & $\begin{array}{l}\text { Handles complex language well. Has operational command of the language, } \\
\text { though with occasional inaccuracies, inappropriacies and misunderstandings in } \\
\text { some situations. Generally handles complex language well and understands } \\
\text { detailed reasoning. }\end{array}$ \\
\hline 6 & Competent user & $\begin{array}{l}\text { Has generally effective command of the language despite some inaccuracies, } \\
\text { inappropriacies and misunderstandings. Can use and understand fairly complex } \\
\text { language, particularly in familiar situations. }\end{array}$ \\
\hline 5 & Modest user & $\begin{array}{l}\text { Has partial command of the language, coping with overall meaning in most } \\
\text { situations, though is likely to make many mistakes. Should be able to handle } \\
\text { basic communication in own field. }\end{array}$ \\
\hline 4 & Limited user & $\begin{array}{l}\text { Basic competence is limited to familiar situations. Has frequent problems in } \\
\text { understanding and expression. Is not able to use complex language. }\end{array}$ \\
\hline 3 & $\begin{array}{l}\text { Extremely limited } \\
\text { user }\end{array}$ & $\begin{array}{l}\text { Conveys and understands only general meaning in very familiar situations. } \\
\text { Frequent breakdowns in communication occur. }\end{array}$ \\
\hline 2 & Intermitted user & $\begin{array}{l}\text { No real communication is possible except for the most basic information using } \\
\text { isolated words or short formulae in familiar situations and to meet immediate } \\
\text { needs. Has great difficulty understanding spoken and written English. }\end{array}$ \\
\hline 1 & Non user & $\begin{array}{l}\text { Essentially has no ability to use the language beyond possibly a few isolated } \\
\text { words. }\end{array}$ \\
\hline $\mathbf{0}$ & $\begin{array}{l}\text { Didn't attempt the } \\
\text { test }\end{array}$ & No assessable information provided. \\
\hline
\end{tabular}

\section{Copyrights}

Copyright for this article is retained by the author(s), with first publication rights granted to the journal.

This is an open-access article distributed under the terms and conditions of the Creative Commons Attribution license (http://creativecommons.org/licenses/by/4.0/). 